\title{
Macroporous epoxy-based monoliths for rapid quantification of Pseudomonas aeruginosa by adsorption elution method optimized for qPCR
}

\author{
Lisa Göpfert ${ }^{1} \cdot$ Julia Klüpfel ${ }^{1} \cdot$ Charlotte Heinritz $^{1} \cdot$ Martin Elsner $^{1} \cdot$ Michael Seidel $^{1}$
}

Received: 1 July 2020 / Revised: 11 September 2020 / Accepted: 16 September 2020 / Published online: 3 October 2020

(C) The Author(s) 2020

\begin{abstract}
Pseudomonas aeruginosa contaminations in tap water systems have caused severe health problems in both hospital and household settings. To ensure fast and reliable detection, culture-independent methods are recommendable. However, the typically low cell number in water samples requires sample enrichment prior to analysis. Therefore, we developed and optimized an adsorption elution method using monolithic adsorption filtration and subsequent centrifugal ultrafiltration that can be combined with culture-independent detection methods. The principle of adsorption of Pseudomonas aeruginosa by hydrophobic and ionic interactions was studied in modified epoxy-based monoliths. Optimized conditions (5-L initial sample volume at $\mathrm{pH} 3$ filtered for 30 min through hydrolyzed monoliths (MAF-OH) and eluted with beef extract glycine buffer at $\mathrm{pH} 9.5$ ) achieved a recovery of $67.1 \pm 1.2 \%$ and a concentration factor of $10^{3}$. For the first time, we therefore present a culture-independent approach for rapid enrichment and subsequent molecular biological quantification of $P$. aeruginos $a$ by qPCR from tap water samples by monolithic adsorption filtration. The total enrichment and quantification process takes $4 \mathrm{~h}$. This work further stresses the versatility of the monolithic adsorption filtration and its possibilities as a concentration tool for culture-independent analytics of pathogenic bacteria in the environment.
\end{abstract}

Keywords Monolith filtration $\cdot$ Pseudomonas aeruginosa $\cdot$ Culture-independent $\cdot$ Adsorption elution

\section{Introduction}

Providing safe drinking water - or lowering risk for workers in contact with technical water - nowadays requires very sensitive analytical techniques to detect and rapidly quantify pathogenic bacteria. Therefore, it is necessary to concentrate bacteria from large water sample volumes prior to subsequent analysis by cultivation-independent methods. Here, traditional sterile filtration has its disadvantages as the filters tend to clog quickly due to matrix components when large water sample

Lisa Göpfert and Julia Klüpfel contributed equally to this work.

Electronic supplementary material The online version of this article (https://doi.org/10.1007/s00216-020-02956-3) contains supplementary material, which is available to authorized users.

Michael Seidel

michael.seidel@tum.de

1 Institute of Hydrochemistry, Chair of Analytical Chemistry and Water Chemistry, Technical University of Munich, Marchioninistr. 17, 81377 Munich, Germany volumes are processed. Monolith-based filtration offers an attractive alternative. Monoliths are homogeneous stationary phases with high porosity. They can be comprised of organic or inorganic material, most often silica [1]. While silica monoliths have a high surface, their limited $\mathrm{pH}$ working range (stability in a $\mathrm{pH}$ range from 2 to 8 ) often excludes them from applications targeting bacterial concentration using adsorption-elution processes [2]. Organic monoliths, in contrast, are easy to synthesize and stable at even extreme $\mathrm{pH}$, which compensates for the lower surface compared with silica monoliths [1, 3]. An overview of different enrichment methods for microorganisms is given in Table 1 .

One of the applications of an organic monolith is the monolithic adsorption filtration which has already been applied efficiently in concentrating different bacteria and viruses from water $[8,9]$. An epoxy-based monolith with free epoxy groups on the filter surface can be synthesized within $1 \mathrm{~h}$ with a defined pore size of $21 \mu \mathrm{m}$ [10]. The production costs of the unfunctionalized monolithic adsorption filters (MAFs) are below $1 €$ per single use MAF. The free epoxide groups allow functionalization for desired adsorption properties in an easy 
Table 1 Overview of different enrichment methods for microorganisms [4-7]

\begin{tabular}{|c|c|c|}
\hline Method & Advantages & Disadvantages \\
\hline Centrifugation & Easy handling & $\begin{array}{l}\text { Loss of non-viable cells possible } \\
\text { Matrix may also be concentrated } \\
\text { Often only size specific }\end{array}$ \\
\hline Immunofiltration & Very specific due to antibody interaction & $\begin{array}{l}\text { Cost intensive due to antibodies } \\
\text { More steps needed for synthesis }\end{array}$ \\
\hline Immunomagnetic separation & Very specific due to antibody interaction & $\begin{array}{l}\text { Cost intensive due to antibodies } \\
\text { Low sample volumes }\end{array}$ \\
\hline Flocculation & Can enrich multiple microorganisms at once & $\begin{array}{l}\text { Time intensive } \\
\text { Based on unspecific interactions }\end{array}$ \\
\hline Membrane filtration & $\begin{array}{l}\text { Automation possible } \\
\text { Defined size range } \\
\text { Different materials possible }\end{array}$ & Dead-end filtration may result in clogged filters \\
\hline Monolithic filtration & $\begin{array}{l}\text { Easily adaptable due to functionalization } \\
\text { Easy and fast synthesis of unfunctionalized filters } \\
\text { Used for different microorganisms } \\
\text { Applicable over a wide range of } \mathrm{pH} \text { values, flow rates, and matrices }\end{array}$ & Sometimes complicated functionalization \\
\hline
\end{tabular}

and fast manner. Different functionalization types of the MAFs have been published, such as hydrolyzed MAFs (MAF-OH) [9] with hydroxyl groups on the MAF surface, MAFs with diethyl aminoethyl groups on the surface (MAFDEAE) [11], and MAFs with the antibiotic polymyxin B immobilized on the pore surface (MAF-PmB) [10]. The retention of bacterial cells on the monolith is based on different interactions such as ionic or hydrophobic interactions, hydrogen bonds, or van der Waals forces. The individual composition of these forces depends on the analyte and the MAF functionalization. Due to the monolith's structure (macroporous with no mesopores), MAF filtration of microorganisms can be performed at high flow rates and with large sample volumes. An overview of different MAF types is given in Table 2. In this study, only BigMAF were used and are referred to as MAF or MAF disks, but with respect to the desired sample volumes also other MAF types could be applied. Additionally, batch or continuous sampling and automation of the whole process is possible and dead-end as well as crossflow applications have been developed [8]. The possibility to process high volumes enables high concentration factors that are crucial for a rapid detection of low cell numbers in environmental samples. While this adsorption elution process is commonly used for the enrichment of viruses, it was first applied to the enrichment of Salmonella sp. and Escherichia coli as early as 1976 using DEAE cellulose columns [12] and adapted for MAFs for Escherichia coli [10] and Legionella sp. [9]. In this work, for the first time, an adaption towards Pseudomonas aeruginosa concentration has been done.

P. aeruginosa is a Gram-negative, biofilm-forming bacterium causing different diseases such as pneumonia, wound infections, and sepsis. It is present in most environmental water bodies, intrinsically resistant to a number of standard
Table 2 Overview of previously published MAF types and their properties. $d$, diameter in $\mathrm{mm} ; h$, height in $\mathrm{mm}[8,10,11,13,14]$

\begin{tabular}{llllll}
\hline MAF type & Flow rate & $\begin{array}{l}\text { Max. sample volume and } \\
\text { filtration time }\end{array}$ & $\begin{array}{l}\text { Elution } \\
\text { volume }\end{array}$ & $\begin{array}{l}\text { Cartridge } \\
\text { type }\end{array}$ & Modification \\
\hline $\begin{array}{l}\text { microMAF } \\
d=4.5\end{array}$ & $10 \mathrm{~mL} \mathrm{~min}^{-1}$ & $300 \mathrm{~mL}$ in $30 \mathrm{~min}$ & $200 \mu \mathrm{L}$ & Glass & $\begin{array}{c}\text {-OH } \\
\text {-Polymyxin } \\
h=6.0\end{array}$ \\
$\begin{array}{l}\text { miniMAF } \\
d=3.7\end{array}$ & $0.7-34 \mathrm{~mL} \mathrm{~min}^{-1}$ & $1000 \mathrm{~mL}$ in $33 \mathrm{~min}$ & & & $\begin{array}{c}\text { B } \\
h=11.8\end{array}$ \\
$\begin{array}{l}\text { BigMAF } \\
d=38.6\end{array}$ & $1 \mathrm{~L} \mathrm{~min}^{-1}$ & $100 \mathrm{~L}$ in $100 \mathrm{~min}$ & Glass & -Antibody \\
$h=10.0$ & & & $20 \mathrm{~mL}$ & Plastic & -OH \\
miniMAF & $50 \mathrm{~mL} \mathrm{~min}^{-1}$ & $1 \mathrm{~L} \mathrm{in} 20 \mathrm{~min}$ & & & -DEAE \\
$d=10.0$ & & & $1 \mathrm{~mL}$ & Plastic & -OH \\
$h=10.0$ & & & & -DEAE \\
\hline
\end{tabular}


antibiotics, and further known to easily acquire new resistances, which makes infections often difficult to treat $[15$, 16]. Because of this, $P$. aeruginosa is especially dangerous for immunosuppressed people, e.g., patients in hospitals or people with chronic illnesses. Due to the biofilm formation, contaminations in the tap water system, e.g., of water meters or at the water tap, are tenacious once they have formed. This is because of the reduced susceptibility of bacteria in a biofilm towards disinfection or antimicrobial agents $[17,18]$. In consequence, $P$. aeruginosa is among the opportunistic premise plumbing pathogens which are of increasing research importance as they are prone to survive and even thrive in these systems $[19,20]$. In recent years, several contaminations of $P$. aeruginosa in tap water systems have gathered public attention. In 2014, several water meters to be installed at kindergartens, hospitals, and retirement homes in Hamburg, Germany, showed contaminations and needed to be changed [21]. Additionally, several outbreaks of nosocomial infections linked to $P$. aeruginosa from water systems have been registered: In France, cases in an oncohematology pediatric unit (2005) [22], and in the ear, nose, and throat department of a hospital (2014) [23]. Additional reports stem from Northern Ireland in several neonatal units (2011-2012) [24] and in the USA in a neonatal intensive care unit (2017) [25]. For contaminated sites, a level of $>150 \mathrm{CFU} 100 \mathrm{~mL}^{-1}$ has been reported [22]. However, P. aeruginosa is also found in technical water systems such as cooling water towers [26] and in several other settings [27]. To prevent their spreading and possible infection outbreaks, thorough monitoring is desirable. In case of a contamination, rapid detection by cultureindependent methods is crucial to cut incubation time short, thus allowing for prompt disinfection measures.

Standard operating procedures for detection of $P$. aeruginosa from water samples rely on culture methods, which take a long time to give dependable results (up to $48 \mathrm{~h}$ ) and which may even have difficulties in capturing the correct number of the target pathogens because they may "hide" in biofilms. Especially with contaminations in tap water systems, time is essential to prevent further infections. Here, cultureindependent analysis methods can give reliable results within hours instead of days. Culture-independent methods are molecular biological assays such as the (quantitative) polymerase chain reaction (qPCR) or, alternatively, flow cytometry, spectroscopic methods (Raman or IR), and immunoassays. Additionally, and in contrast to culture, these methods can detect bacteria also in a viable but non-culturable (VBNC) state, which $P$. aeruginosa is known to enter if insufficient disinfection took place [28]. As these VBNC bacteria can later be resuscitated [29], they need to be captured to assess the success of disinfection measures correctly. This is of particular importance not only in drinking water systems but also in technical plants.

To provide a sufficiently high number of bacteria for application of these culture-independent methods, we present the development and optimization of a concentration method for $P$. aeruginosa from tap water using MAF filtration in combination with centrifugal ultrafiltration. Subsequently, the feasibility of culture-independent detection was demonstrated using qPCR as an approach that avoids error-prone quantification via culture and which ensures a rapid detection. An overview of the procedure is given in Fig. 1.

\section{Experimental}

\section{Materials and instrumentation}

All chemicals, unless stated otherwise, were purchased from Sigma-Aldrich, subsidiary of Merck (Darmstadt, Germany). LB media, agar agar, diethylamine, glycerine, PD-tips, and sodium hypochlorite were purchased from Carl Roth (Karlsruhe, Germany). Polyglycerol-3-glycidyl ether (CL9)

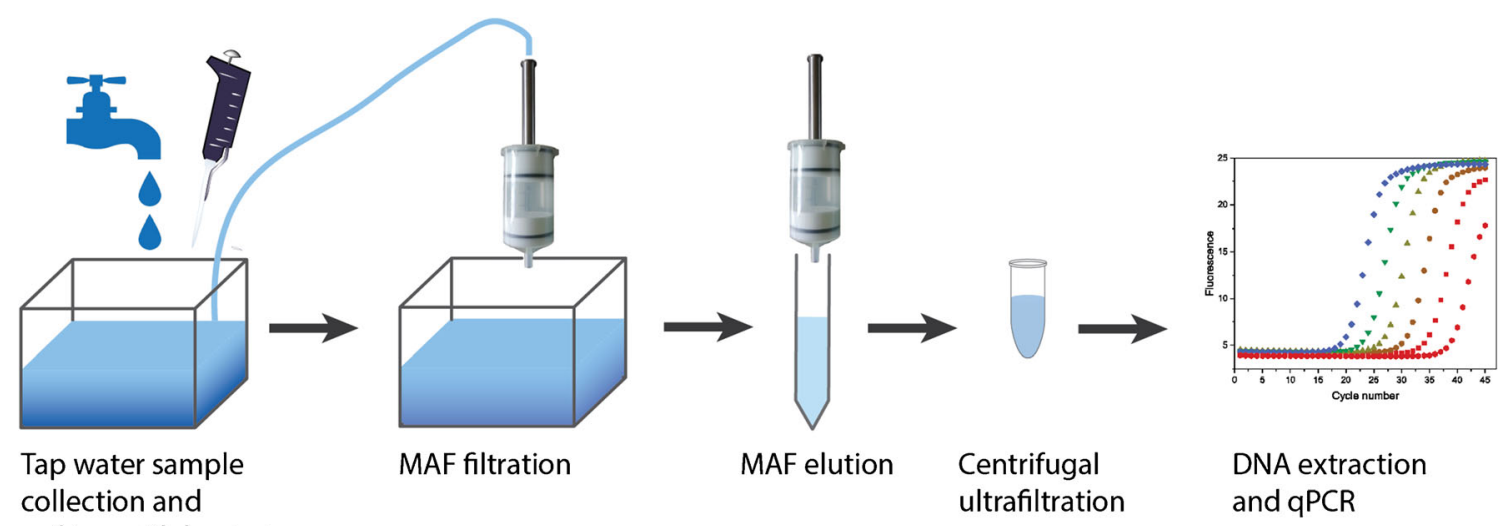

Fig. 1 Schematic overview of the total procedure. A tap water sample is collected and spiked with bacteria. Subsequent MAF filtration and elution is followed by centrifugal ultrafiltration and DNA extraction for analysis with qPCR 
was obtained from ipox chemicals (Laupheim, Germany). All oligonucleotides were synthesized by Eurofins Genomics (Ebersberg, Germany), purchased in lyophilized form and dissolved in nuclease-free water. Primers for detection of the $P$. aeruginosa regA gene were designed in house. For genomic DNA extraction, the extraction kit GeneJET Genomic DNA Purification Kit by Thermo Scientific (Waltham, USA) was used. Photometric measurements were performed on a NanoPhotometer by Implen (Munich, Germany). For qPCR, the Luna ${ }^{\circledR}$ Universal qPCR Master Mix by New England Biolabs (Ipswitch, USA) was used. For all experiments, ultrapure water was used, unless stated otherwise. Nuclease-free water was purchased from Invitrogen $A G$ (Carlsbad, USA). A bacterial isolate of Pseudomonas aeruginosa (ATCC27853) was received from the Bavarian Health and Food Safety Authority. Viable bacteria were handled in laboratories approved for biosafety level 2 .

\section{Field emission scanning electron microscopy imaging}

Field emission scanning electron microscopy (FESEM) images from MAF filters were obtained using a Sigma VP 300 FE-SEM (Carl Zeiss AG, Germany), run in low vacuum mode. The inner MAF structure was analyzed by cutting out $5 \times 5 \mathrm{~cm}$ rectangles in the center of the MAF and then halving them horizontally using a scalpel. The upper side of the lower half was then measured in different magnifications and analyzed using ImageJ.

\section{Bacteria cultivation}

$P$. aeruginosa from cryo-culture (stored at $-80^{\circ} \mathrm{C}$ ) was cultivated overnight $\left(37^{\circ} \mathrm{C}\right)$ in $\mathrm{LB}$ media to be used for further experiments. Appropriate dilutions were further cultivated on LB agar plates (own production) overnight $\left(37^{\circ} \mathrm{C}\right)$. For filtration experiments, the bacterial cell number in liquid culture of $P$. aeruginosa was calculated from optical density measurements at $600 \mathrm{~nm}\left(\mathrm{OD}_{600}\right)$. A calibration curve with OD measurements from fresh overnight culture was obtained by plating dilutions on agar plates and calculating the $\mathrm{CFU} \mathrm{mL} \mathrm{m}^{-1}$.
The empirical formula: cell number in $\mathrm{CFU} \mathrm{mL} \mathrm{L}^{-1}=\left(\mathrm{OD}_{600}-\right.$ $0.0033) /\left(1.1244 \cdot 10^{8}\right)$ was obtained and used for all cell number calculations. All cell numbers were obtained using this process (details can be found in the Electronic Supplementary Material (ESM)).

\section{Monolithic adsorption filter disk production}

MAFs were produced by self-polymerization of an epoxy-based resin [10] with minor adjustments. Briefly, a 60:40 (v/v) mixture of toluene and tert-butyl methyl ether was tempered at $29{ }^{\circ} \mathrm{C}$. The catalyst trifluoride diethyl etherate $\left(\mathrm{BF}_{3} \cdot \mathrm{Et}_{2} \mathrm{O}\right)$ in 1,4-dioxane $(1: 10(\mathrm{v} / \mathrm{v})$ dilution) was added to the mixture $(1.25 \%$ $(\mathrm{v} / \mathrm{v})$ of the total volume) and mixed thoroughly. The monomer polyglycerol-3-glycidyl ether (CL9) (ratio 20:80 (v/v) monomer/porogen) was added and mixed thoroughly before pouring the mixture into PTFE molds (inner diameter $38.6 \mathrm{~mm}$, inner height $10.0 \mathrm{~mm}$ ) and incubating at $29{ }^{\circ} \mathrm{C}$ for $45 \mathrm{~min}$. Afterwards, the MAF disks (38.6- $\mathrm{mm}$ diameter, $10.0-\mathrm{mm}$ height) [8] were removed from the polymerization molds, stored in methanol overnight to stop the reaction, and air-dried at room temperature (Fig. 2). Reaction schemes for the different functionalizations are shown in Fig. 3. For functionalization, the MAF disks were constructed to MAF modules in 50-mL plastic dispenser tips (PD-tip) and consisting of a PTFE support plate with bore holes (diameter $2 \mathrm{~mm}$ ), an O-ring (38.6 $\mathrm{mm}$ in diameter, nitrile butadiene rubber (NBR) 70), a MAF disk, and a PTFE fitting for connection to tubes. The MAF disks were washed with ultrapure water before functionalization by connecting the MAF modules to a peristaltic pump and continuously pumping ultrapure water through the system $(10 \mathrm{~min})$. Afterwards, the respective functionalization solutions were circulated through the system according to the functionalization procedures displayed in Table 3 (schematic overview in Fig. 4). The functionalized MAF disks were stored in ultrapure water at $4{ }^{\circ} \mathrm{C}$ until further use.
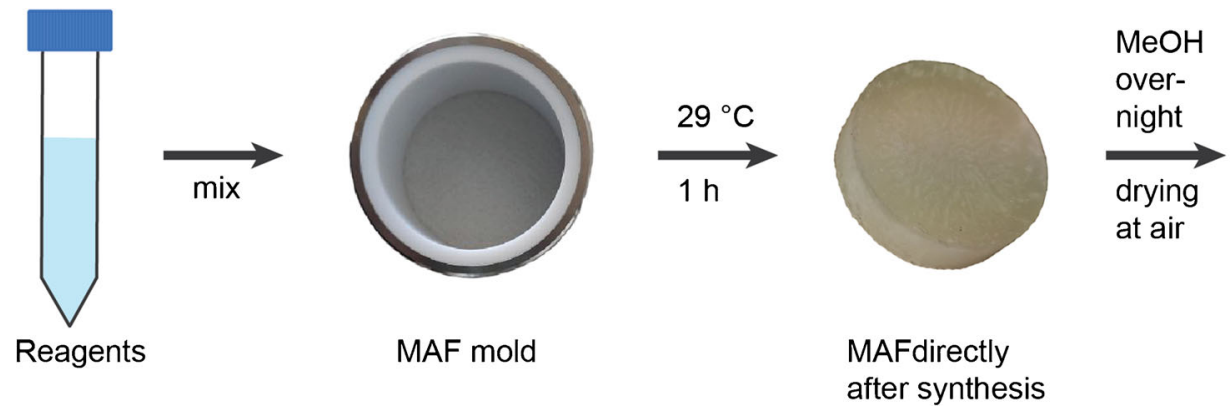

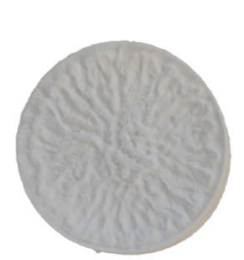

Dried MAF

Fig. 2 Schematic overview of the MAF production. The reagents are mixed and poured in a MAF mold. After incubation for $1 \mathrm{~h}$ at $29{ }^{\circ} \mathrm{C}$, the MAF is removed from the mold and put in $\mathrm{MeOH}$ to end the polymerization. After removal of the $\mathrm{MeOH}$, the MAFs are air-dried 

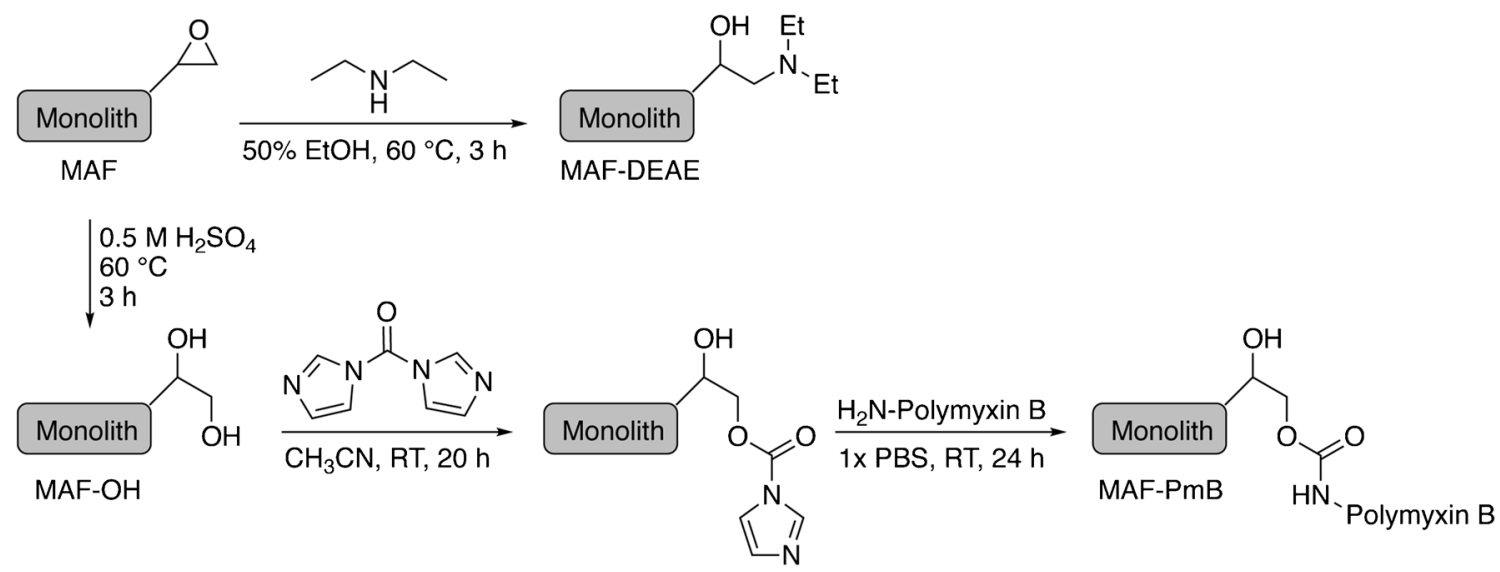

Fig. 3 Reaction schemes for functionalization of MAFs to obtain MAF-OH, MAF-DEAE, and MAF-PmB

\section{Filtration of tap water samples}

Tap water samples were taken in different volumes (1-L glass bottle, 5-L polypropylene high breast bottle, or 10-L polyethylene canister) and, if necessary, $\mathrm{pH}$ value was adjusted to the desired $\mathrm{pH}$ using $37 \%$ hydrogen chloride. The desired amount of $P$. aeruginosa was spiked shortly before filtration. For all optimization experiments, cells for $10^{8} \mathrm{CFU} \mathrm{L}^{-1}$ final concentration, and for calibration experiments, the amounts for final concentrations $\left(1 \cdot 10^{4}-1 \cdot 10^{8} \mathrm{CFU} / \mathrm{L}\right)$ were added. If heatinactivated bacteria were used, the inactivation was done at $80^{\circ} \mathrm{C}$ for $30 \mathrm{~min}$. A MAF module was connected to a peristaltic pump (Pumpdrive 5206 Peristaltic Pump, Heidolph, Germany) with a silicone tube (Maprene Tube, WatsonMarlow, Wilmington) and a 10-L PE canister was placed under the outlet of the MAF module to collect the filtrate. Tap water was used to flush the system and adjust the flow rate to approx. $180 \mathrm{~mL} \mathrm{~min}{ }^{-1}$. Filtration was done by inserting the water inlet into the tap water sample and using the adjusted flow rate. After filtration of the whole sample, the MAF module was flushed with air and filled with elution buffer $(20 \mathrm{~mL})$. Elution took place in a three-step process. Each step consisted of an incubation ( $2 \mathrm{~min}$ ) and elution of one-third of the elution buffer at a flow rate of approx. $110 \mathrm{~mL} \mathrm{~min}^{-1}$. Used elution buffers were carbonate buffer (sodium carbonate $(0.150 \mathrm{mM})$ and sodium bicarbonate $(0.350 \mathrm{mM})$ in ultrapure water; pH 9.6), high-salt buffer (sodium chloride (14.99 mM) and HEPES (4-(2-hydroxyethyl)-1-piperazineethanesulfonic acid) $(0.500 \mathrm{mM})$ in ultrapure water; $\mathrm{pH} 7$, adjusted with $32 \%$ sodium hydroxide), glycine buffer (5.00 $\mathrm{mM}$ in ultrapure water; $\mathrm{pH} 9.5$, adjusted with $32 \%$ sodium hydroxide), beef extract glycine buffer (BEG, beef extract $(30.0 \mathrm{~g})$ and glycine $(0.505 \mathrm{M})$ in $1 \mathrm{~L}$ of ultrapure water; $\mathrm{pH} 9.5$, adjusted with $32 \%$ sodium hydroxide), and Pluronic ${ }^{\circledR}$ F68 solution (Pluronic $®$ F68 (1\%)).

\section{Centrifugal ultrafiltration and DNA extraction}

Centrifugal ultrafiltration (CeUF) was performed using Vivaspin 20 Membrane 50,000 columns (Sartorius, Stonehouse, UK). The eluate of the MAF filtration was centrifugated $(5000 \mathrm{rpm})$ until the final volume was $0.5-1 \mathrm{~mL}$. The filter was washed with sterile PBS buffer and the volume was adjusted to $1.5 \mathrm{~mL}$ with PBS buffer. One milliliter was used for DNA extraction while the remaining $0.5 \mathrm{~mL}$ was stored at $-20{ }^{\circ} \mathrm{C}$.
Table 3 Overview of functionalization procedures for MAF disks. $M A F-O H$, hydrolyzed MAFs; MAF-DEAE, MAFs with diethyl aminoethyl functionalization; $M A F-P m B$, MAFs with polymyxin B functionalization [9-11]

\begin{tabular}{llll}
\hline Functionalization & Functionalization solution & Circulation time & Temperature \\
\hline MAF-OH & 0.5 M sulfuric acid & $3 \mathrm{~h}$ & $60{ }^{\circ} \mathrm{C}$ \\
& Ultrapure water & $15 \mathrm{~min}$ & $\mathrm{RT}$ \\
MAF-DEAE & $10 \%$ diethylamine in EtOH$/ \mathrm{H}_{2} \mathrm{O}(50 / 50 ; \mathrm{v} / \mathrm{v})$ & $3 \mathrm{~h}$ & $60{ }^{\circ} \mathrm{C}$ \\
& Ultrapure water & $15 \mathrm{~min}$ & $\mathrm{RT}$ \\
MAF-PmB & $0.5 \mathrm{M}$ sulfuric acid & $3 \mathrm{~h}$ & $60{ }^{\circ} \mathrm{C}$ \\
& Acetonitrile $(\mathrm{ACN})$ & Until filtrate was clear & $\mathrm{RT}$ \\
& 2 mg mL ${ }^{-1} 1,1^{\prime}$-carbonyl-diimidazole in ACN & Overnight & $\mathrm{RT}$ \\
& ACN, followed by PBS buffer & Until filtrate was clear & $\mathrm{RT}$ \\
& $0.02 \mathrm{mg} \mathrm{mL}^{-1}$ polymyxin B in PBS buffer & $24 \mathrm{~h}$ & $\mathrm{RT}$ \\
& PBS buffer and carbonate buffer & Until filtrate was clear & $\mathrm{RT}$
\end{tabular}




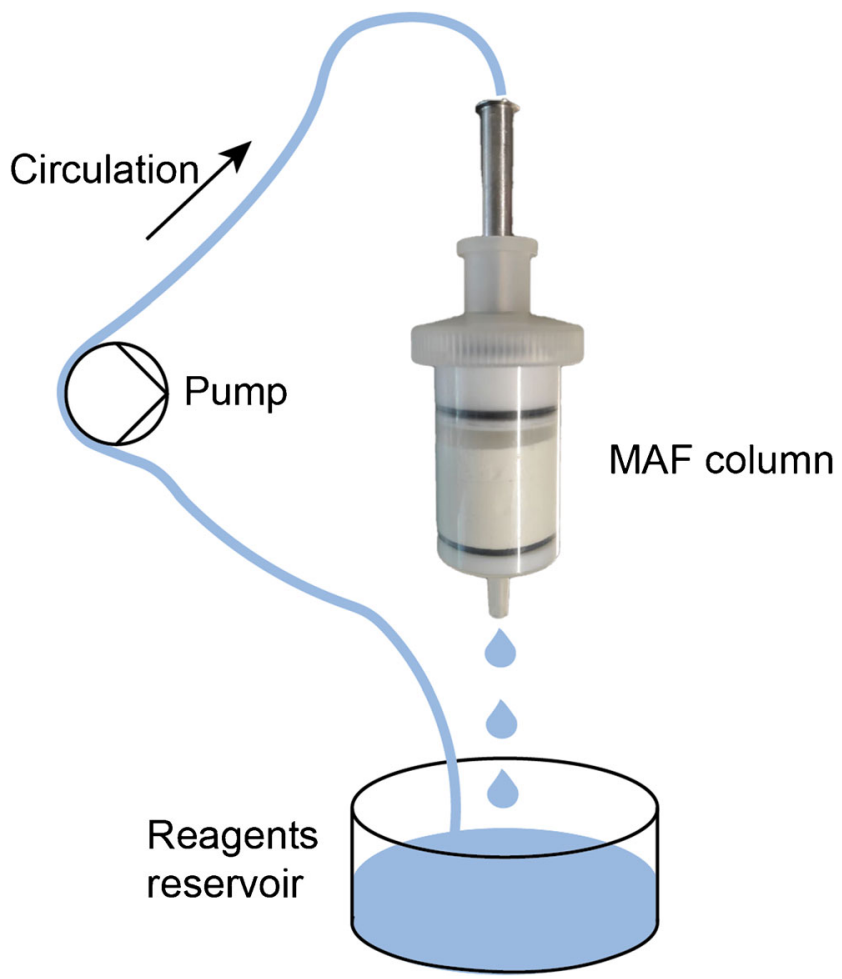

Fig. 4 Schematic overview of the MAF functionalization. Three MAFs are functionalized at the same time by circulating the reagent solutions continuously through the MAF for the respective amount of time

DNA extraction was performed using the GeneJET Genomic DNA Purification Kit by Thermo Scientific (Waltham, USA) according to manufacturer's guideline. Initial cell harvesting was accomplished by centrifugation of the sample $(5000 \times \mathrm{g}, 10 \mathrm{~min})$. DNA extracts were stored at $-20{ }^{\circ} \mathrm{C}$.

\section{qPCR}

Primer sequences for regA detection in $P$. aeruginosa are shown in Table 4 and additional information about specificity of the primer pair including cross-reactivity experiments, qPCR procedure, and calibration experiments can be found in the ESM. The amplicon length is $141 \mathrm{bp}$. All qPCR experiments were carried out on a LightCycler 480 (Roche Diagnostics, Rotkreuz, Switzerland). The assay was performed according to the manufacturer's guidelines. Briefly, for every reaction, $10 \mu \mathrm{L}$ Luna Master Mix (New England Biolabs, Ipswitch, USA), $0.5 \mu \mathrm{L}$ forward (FWD) primer $(10 \mu \mathrm{M}), 0.5 \mu \mathrm{L}$ reverse (REV) primer $(10 \mu \mathrm{M})$, and $7 \mu \mathrm{L} \mathrm{H}_{2} \mathrm{O}$ were combined in a master mix. To this master mix, $2 \mu \mathrm{L}$ of the DNA sample of interest was added. Non-target controls were also included in every qPCR measurement $(18 \mu \mathrm{L}$ of the master mix described above and $2 \mu \mathrm{L} \mathrm{H}_{2} \mathrm{O}$ ).

\section{Results and discussion}

\section{Rapid quality control for MAFs using FESEM images}

To ensure successful, reproducible synthesis of MAFs, the main filter parameters should be checked for every synthesis batch. However, an easy and fast quality control for MAF has so far been missing. Mercury intrusion porosimetry was used successfully in the past, but no batch-to-batch control in a short timeframe is possible with this method. For this reason, the application of FESEM imaging analyzed with ImageJ to measure pore sizes and polymer globule diameter was tested. The following FESEM images for pore sizes (Fig. 5a) and polymer globule diameters (Fig. 5c) exemplarily show pristine MAFs from batches synthesized for this work. The observed mean pore size was $22.30 \pm 6.30 \mu \mathrm{m}$ corresponding well to the literature value of $22.5 \pm 9.0 \mu \mathrm{m}$ [10]. Functionalized MAF-OH showed a mean pore size of $22.34 \pm 5.58 \mu \mathrm{m}$ corresponding well with the mean pore size of pristine MAFs. Thus, functionalization does not change the pore size. For the mean polymer globule diameter, a value of $4.61 \pm 0.56 \mu \mathrm{m}$ was found with a relatively homogeneous size distribution (Fig. 5d), indicating a continuous and homogeneous polymerization process. Thus, FESEM measurements allow for a rapid quality assessment for different MAF batches that is important to ensure a high reproducibility of the overall method.

\section{Comparison of MAF functionalization types for $P$. aeruginosa filtration}

Three different MAF functionalization types (MAF-OH, MAF-DEAE, and MAF-PmB) were tested under the respective standard conditions to identify the MAF functionalization with the most promising results for further experiments with P. aeruginosa. The standard conditions were MAF-OH: 10-L sample volume, $\mathrm{pH}$ 3, BEG elution buffer [9]; MAF-DEAE: 1-L sample volume, $\mathrm{pH}$ 7, BEG elution buffer [11]; MAFPmB: 1-L sample volume, $\mathrm{pH} \mathrm{4,} \mathrm{carbonate} \mathrm{elution} \mathrm{buffer}$ [10]. An overview of recoveries is shown in Fig. 6. The number of $P$. aeruginos a cells on the MAF could not be calculated directly as no reliable concentrations of the filtrate could be determined by qPCR due to the low number of cells in the filtrate. Therefore, recovery was used to quantify the retention and elution process and, unless stated otherwise, calculated as

Table 4 Primers for specific amplification of $P$. aeruginosa DNA in qPCR

\begin{tabular}{llll}
\hline $\begin{array}{l}\text { Target/ } \\
\text { gene }\end{array}$ & Primer & Sequence $\left(5^{\prime} \rightarrow 3^{\prime}\right)$ & Reference \\
\hline regA gene & $\begin{array}{l}\text { PaRegFP } \\
\text { PaRegRP }\end{array}$ & CACAGTGCAGCATCGAGTACCT & This work \\
& & & \\
\hline
\end{tabular}



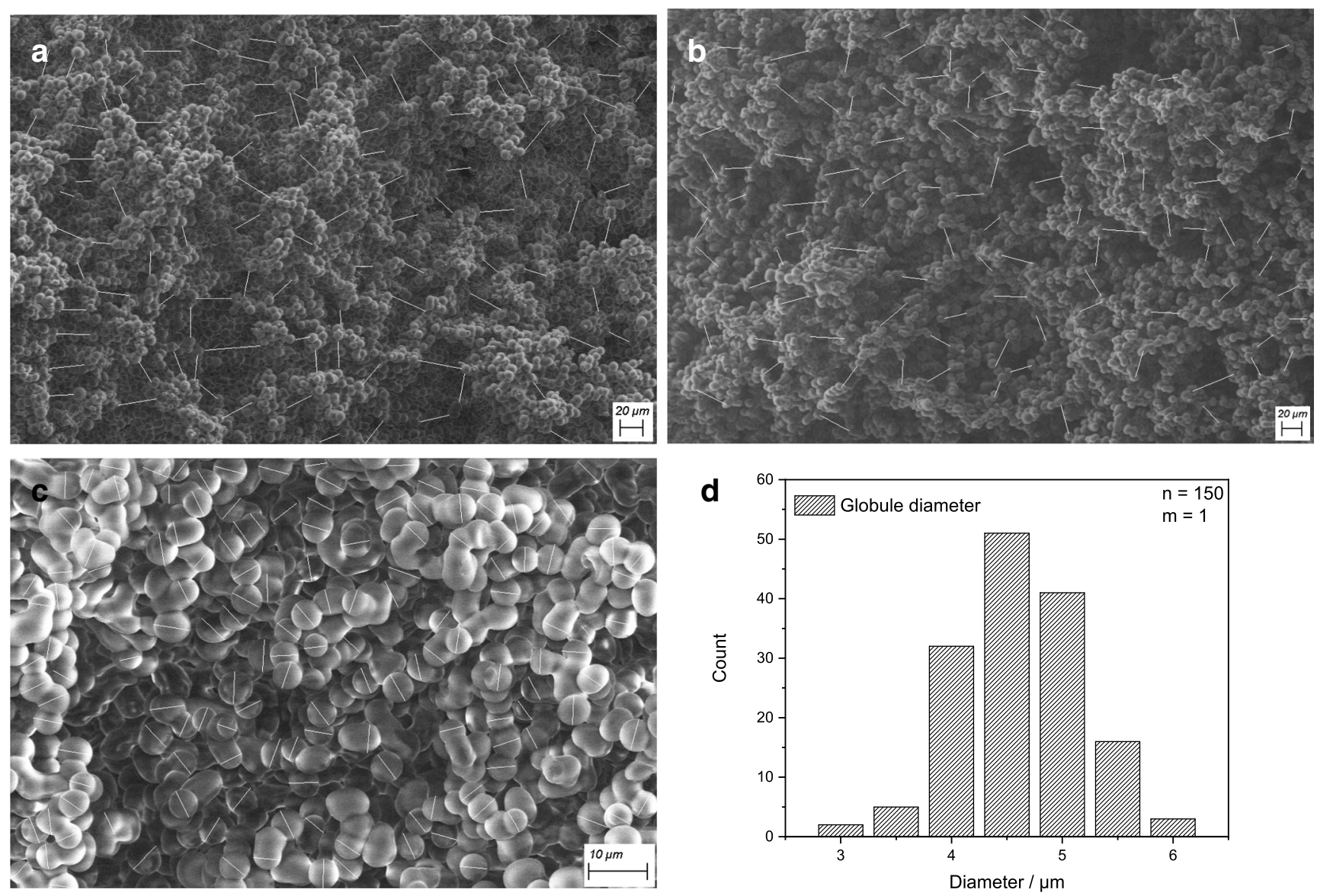

Fig. 5 FESEM images for pristine MAF pore size (a), OH-functionalized MAF pore size (b), polymer globule diameter (c) with indicated measurement lines ( $n=100$ for pores and $n=150$ for globules) and globule diameter size distribution (d)

the ratio of the total number of cells found in the eluate by qPCR after filtration and the total number of cells in the initial sample. Detailed information on how recoveries were obtained can be found in the ESM. Initial spiked concentration of

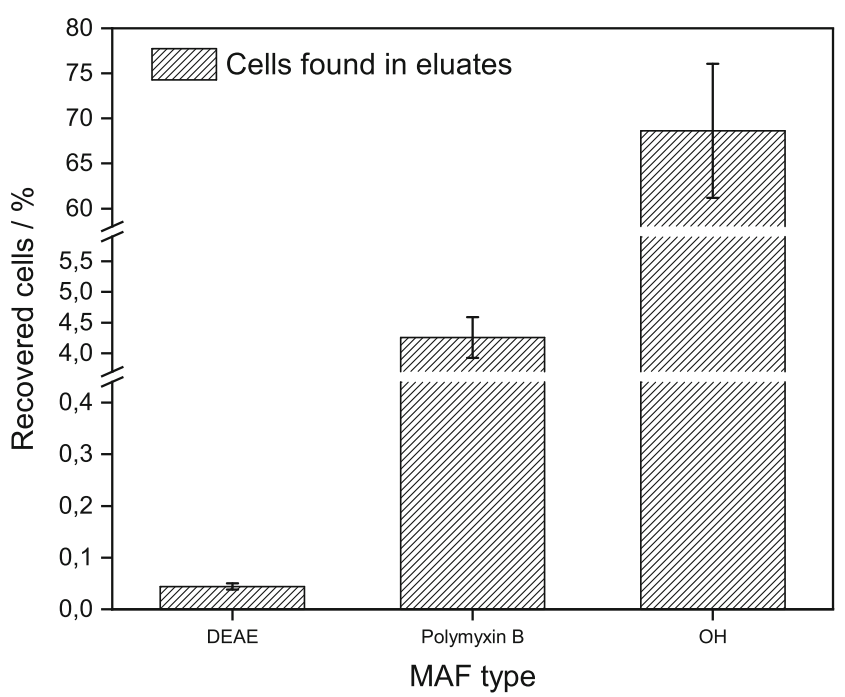

Fig. 6 Recoveries of different MAF functionalization types: DEAE (MAF-DEAE), polymyxin B (MAF-PmB), OH (MAF-OH); $n=3$
P. aeruginosa was $10^{8} \mathrm{CFU} \mathrm{L}^{-1}$. While MAF-DEAE and MAF-PmB only show a recovery of $0.04 \pm 0.01 \%$ and $4.3 \pm$ $0.3 \%$, respectively, MAF-OH shows a remarkably higher recovery of $68.6 \pm 7.4 \%$. Unspecific retention of bacterial cells occurs only to a very minor extent as is evident by the recovery for MAF-DEAE $(0.04 \pm 0.01 \%)$ which is seen as a reference for unspecific binding in this work. Additional recovery experiments with MAF-DEAE and different elution buffers as well as different filtration techniques (one-time filtration, repeated filtration of the same sample, and circulating filtration) have been carried out (data in ESM) but did not yield significantly better results. MAF-PmB uses a surfaceactive antibiotic as the affinity ligand while MAF-DEAE and MAF-OH make use of electrostatic interactions between the MAF surface and the bacteria for retention of the analyte. The MAF-OH seems to offer the positively charged bacteria (due to acidification) high interaction possibilities for electrostatic interaction compared with the MAF-DEAE, where almost no interaction takes place between the MAF surface and the negatively charged bacteria surface (at neutral $\mathrm{pH}$ due to lipopolysaccharide (LPS) structures presented on the surface). The LPS structure in P. aeruginosa is typical for Gramnegative bacteria consisting of lipid A, inner and outer cores, 
and O-antigen with variations depending on the strain (detailed information in [30]) and thus is positively charged at $\mathrm{pH} 3$ and negatively charged at neutral $\mathrm{pH}$. The main interaction properties are stated to be hydrogen bonds. Based on these results, MAF-OH was chosen for further optimization of the filtration process.

\section{Comparison of elution buffers}

Five different elution buffers (BEG buffer, high-salt buffer, carbonate buffer, glycine, and Pluronic ${ }^{\circledR}$ F68 solution) were evaluated for filtration with MAF-OH. The applied MAF process was the same for all (10-L initial sample volume, sample $\mathrm{pH}$ 3, 20-mL elution volume). Spiked $P$. aeruginosa cell concentration was $10^{8} \mathrm{CFU} \mathrm{mL}^{-1}$. Figure 7a shows an overview of the recoveries. While four buffers show relatively similar values with Pluronic ${ }^{\circledR}$ F68 solution $(8.6 \pm 0.3 \%)$, carbonate buffer $(8.8 \pm 0.7 \%)$, high-salt buffer $(11.6 \pm 0.6 \%)$, and glycine buffer $(17.5 \pm 1.5 \%)$, the combination of glycine with beef extract (BEG buffer) gives a significantly higher recovery of $57.0 \pm 3.0 \%$. This buffer combines the desorption properties of a change in $\mathrm{pH}$ (from $\mathrm{pH} 3$ in the sample to $\mathrm{pH} 9.5$ in the elution buffer) with proteins present therefore breaking the interactions between the cells and the monolith surface. While the change in $\mathrm{pH}$ changes the net charge of the bacteria, the protein uses van der Waals forces and hydrophobic interactions to remove the cells from the filter and therefore reduces the electrostatic interactions present in the adsorption process. Thus, BEG buffer was the elution buffer of choice for further experiments.

\section{Optimization of initial sample volume}

While the original MAF-OH filtration protocol for MAF with 3.86-cm diameter and 1-cm height states 10-L initial sample volume [9], it was aimed on finding a lower sample volume

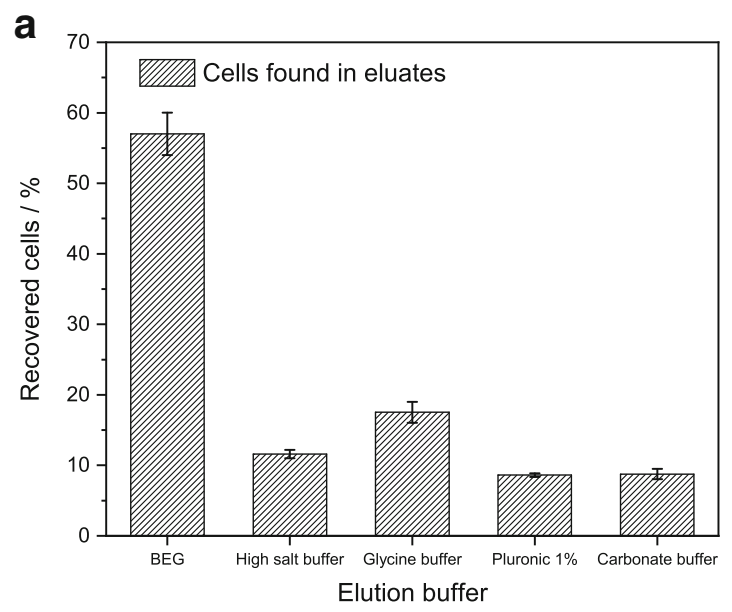

with reasonably high recovery to facilitate an easier sample collection. Here, three different sample volumes $(1 \mathrm{~L}, 5 \mathrm{~L}$, and $10 \mathrm{~L}$ ) were tested under the same conditions (MAF-OH, $\mathrm{pH} 3$ as sample $\mathrm{pH}$, and $\mathrm{BEG}$ elution buffer, $10^{8} \mathrm{CFU} \mathrm{L}^{-1}$ spiked $P$. aeruginosa). With increasing sample volume from 1 to $5 \mathrm{~L}$, a notable increase in recovery from $23.0 \pm 0.4 \%$ to $67.1 \pm$ $1.2 \%$ was observable (Fig. 7b). One explanation for this is the distribution of the $P$. aeruginosa cells within the MAF: With a lower sample volume, the bacteria only attach to the first part of the cylindrical monolith structure while with higher sample volume, several absorption and desorption events occur before the cells finally stick to the MAF. This leads to an even distribution of the bacterial cells over the whole filter at higher sample volumes and thus higher recovery using the same elution protocol. However, a further doubling of the sample volume from 5 to $10 \mathrm{~L}$ only resulted in a minor increase in recovery up to $68.6 \pm 7.4 \%$. As is evident from the differing recoveries for the 10-L samples from both experiments, an interbatch variance can be seen, while the intracharge variance is relatively low. Therefore, it is important to perform quality control of each MAF charge to prevent variances in recovery values. Due to the lower filtration time, the easier handling, and the higher reproducibility (as indicated by the lower standard deviation), the optimal filtration volume for the assay was set at $5 \mathrm{~L}$ for P. aeruginosa filtration.

\section{Adjustment of sample pH}

To evaluate the efficiency of the filtration procedure at different $\mathrm{pH}$ values with MAF-OH, sample $\mathrm{pH}$ values between $\mathrm{pH} 3$ and $\mathrm{pH} 4$ (in 0.2 intervals) as well as $\mathrm{pH} 5,6$, and 7 were tested. Beforehand, culturability of $P$. aeruginos $a$ under the tested conditions in tap water was investigated, as the goal was to find a filtration procedure that would allow subsequent detection via culture. This would then enable the use of cell culture as a confirmatory quantification method, as it is still

b

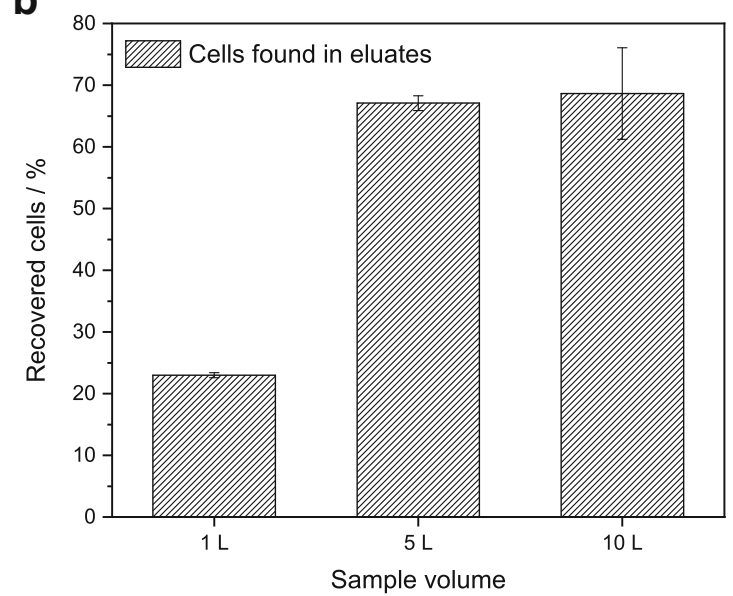

Fig. 7 Recoveries found using different elution buffers (a) and initial sample volumes (b) for filtration with MAF-OH at $\mathrm{pH} 3, n=3$ 
a

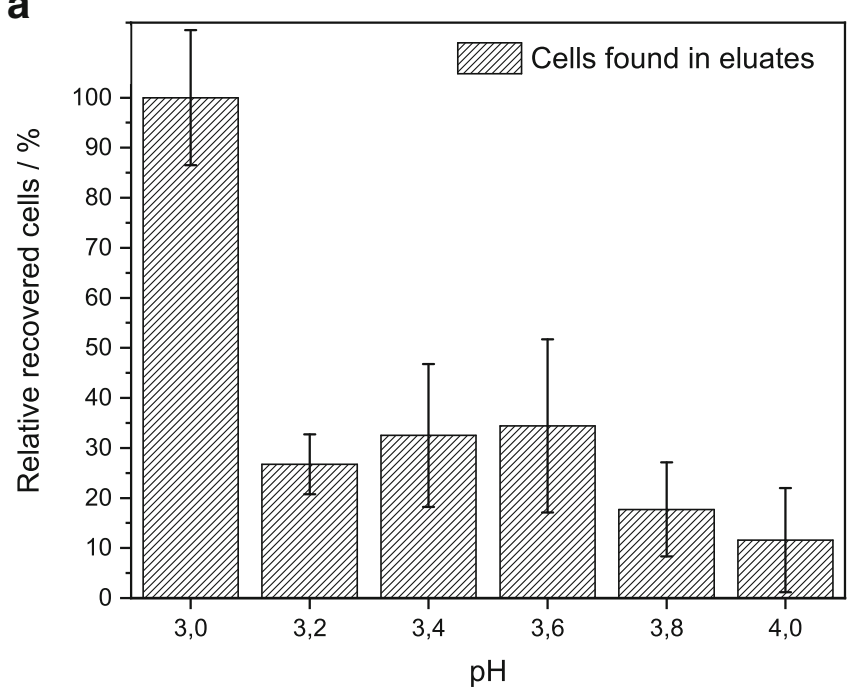

b

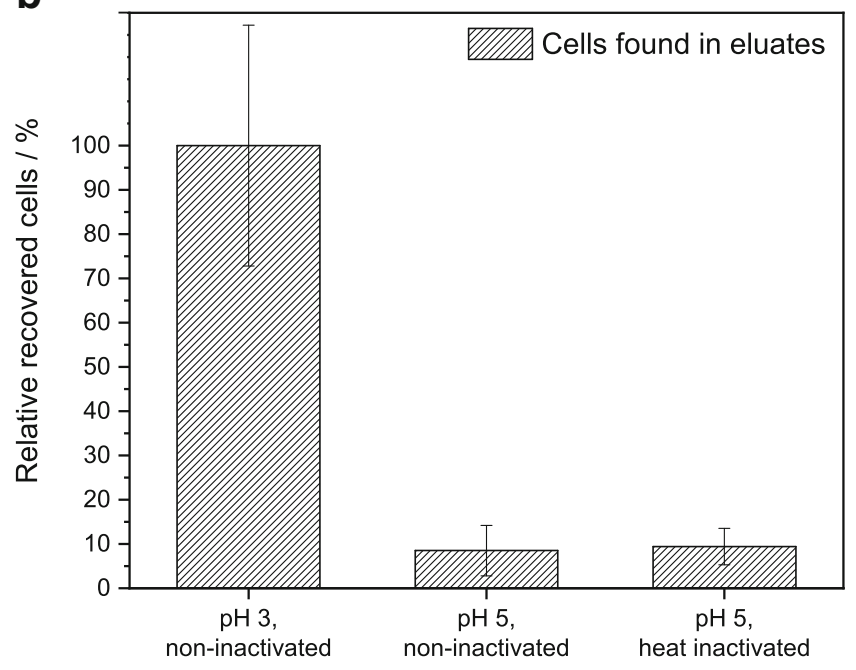

Fig. 8 Recoveries of filtrations with different initial sample pH (a) and viable or heat-inactivated cells at pH 3 and pH 5 (b) with 5-L sample volume, MAF-OH disks, and BEG elution buffer. Recovery for $\mathrm{pH} 3$ and viable cells was set at $100 \%, n=3$

the gold standard method despite the high time expenditure. For $P$. aeruginosa, growth on agar plates was observed for all $\mathrm{pH}$ values above $\mathrm{pH} 3.3$ (overgrown after overnight incubation) and no growth was observed for $\mathrm{pH}$ values below $\mathrm{pH} 3.2$ (no colonies visible), indicating a change in physiology at these $\mathrm{pH}$ values. This result is comparable with the result of another study investigating the effect of low $\mathrm{pH}$ values on the survival of $P$. aeruginosa [31] while a different study found good bacterial growth for $\mathrm{pH}$ higher than 3.8 [32]. For all filtrations, the cultivated $P$. aeruginos $a$ samples were acidified before filtration and the optimized protocol (MAF-OH, 5-L initial sample volume, BEG elution buffer) was used. Spiked $P$. aeruginosa cell concentration was $10^{8} \mathrm{CFU} \mathrm{L}^{-1}$. As is visible in the relative recoveries with $\mathrm{pH} 3$ set to $100 \%$ displayed in Fig. 8a, good retention and elution of the bacteria could be achieved for a sample pH of 3.0 only. Filtrations at pH 3.2 and higher showed significantly lower recoveries with the lowest recovery being at $\mathrm{pH} 4.0(\mathrm{pH} 3.2: 26.7 \% \pm 5.3 \%$; pH 3.4: $32.5 \% \pm 12.72 \%$; pH 3.6: $34.4 \% \pm 15.45 \%$; pH 3.8: $17.7 \% \pm 8.4 \% ; \mathrm{pH} 4: 11.6 \% \pm 9.3 \%)$. Relative recoveries for $\mathrm{pH} 5, \mathrm{pH} 6$, and $\mathrm{pH} 7$ were $23.2 \%, 17.0 \%$, and $10.6 \%$, respectively. Thus, it was concluded that at filtration conditions where $P$. aeruginosa are culturable, no good retention and following elution is possible. The recoveries show higher values than for unspecific binding; hence, a specific interaction between the cells and the MAF surface takes place. Spiked cultivated $P$. aeruginos $a$ which were non-culturable at $\mathrm{pH} 3$ seem to be adsorbed on the surface of MAF-OH much better than culturable cells at higher $\mathrm{pH}$. To evaluate the correlation between culturability and filtration efficiency, additional experiments using both heat-inactivated $P$. aeruginosa and viable cells for spiking were carried out (recoveries in Fig. $8 b$ ). For comparison, $\mathrm{pH} 3$ with cells that were culturable prior to acidification was set at $100 \%$ recovery (standard deviation $\pm 27.2 \%$ ). At a sample $\mathrm{pH}$ of 5 , the relative recovery for heatinactivated and culturable cells was $9.4 \% \pm 4.1 \%$ and $8.5 \% \pm$ $5.7 \%$, respectively. This leads to the conclusion that the filtration efficiency correlates with the sample $\mathrm{pH}$ value but not the culturability status of the bacteria. A change in outer membrane chemistry and consequently a change in the interaction between the monolith's surface and the outer membrane might induce the higher retainability at $\mathrm{pH} 3$. As $P$. aeruginosa cells are not culturable after acidification to $\mathrm{pH} 3$, a live-dead discrimination or detection via culture after filtration using the current setup is not possible, but culture-independent

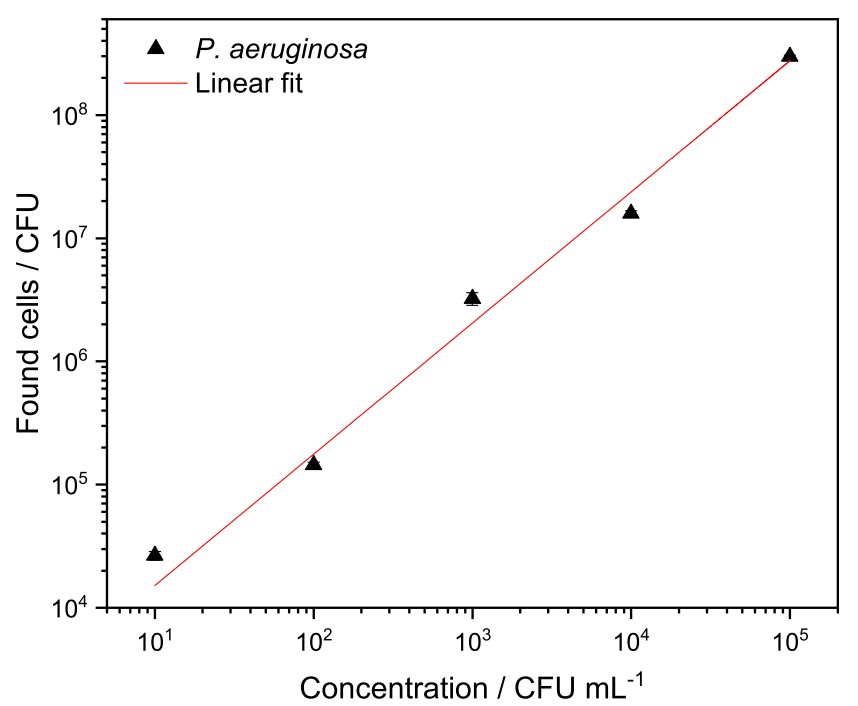

Fig. 9 Linear range of cells found in $1.5-\mathrm{mL}$ eluate against concentration in 5-L initial sample volume at $\mathrm{pH} 3$ concentrated with MAF-OH and eluted with BEG buffer. $y=(3.11 \pm 0.20)+(1.07 \pm 0.04) \cdot \mathrm{x} . n=3$. The error bars are smaller than the symbols indicating the values and thus not clearly visible 
detection methods can be used for the successful quantification after filtration.

\section{Calibration of the final setup}

Based on the optimization process, a calibration using the best filtration conditions for highest recovery of $P$. aeruginosa was carried out. At a sample $\mathrm{pH}$ of 3, 5-L sample volume, filtration with MAF-OH, and elution with BEG buffer, five different concentrations of $P$. aeruginos $a$ spiked in tap water $\left(1 \cdot 10^{4}-1\right.$. $10^{8} \mathrm{CFU} / \mathrm{L}$ ) as well as a blank sample (tap water) were concentrated. The linear range of the calibration is displayed in Fig. 9. A concentration factor of $3 \cdot 10^{3}$ in under $1 \mathrm{~h}$ was achieved by reducing the initial volume of $5 \mathrm{~L}$ to a final volume of $1.5 \mathrm{~mL}$ after filtration and centrifugal ultrafiltration. The filtration efficiency (recovery rate of $67.1 \pm 1.2 \%$ ) is included in the calibration line so that it can be used to calculate the initial sample concentration from the total number of detected cells in the eluate with the quantification method of choice.

\section{Conclusion}

In this work, a new adsorption-elution-based method for the concentration of water samples using monolithic adsorption filtration was developed to enrich $P$. aeruginosa from tap water. Different functionalization types, sample volumes, elution buffers, and sample $\mathrm{pH}$ were tested to establish the most suitable conditions. The final protocol allows quantitative enrichment of $P$. aeruginosa from 5-L initial volume at $\mathrm{pH} 3$ using hydrolyzed MAF and BEG elution buffer. Combined with subsequent centrifugal ultrafiltration, 5-L samples could be concentrated to a final volume of $1.5 \mathrm{~mL}$, corresponding to a concentration factor of $3 \cdot 10^{3}$. Currently, with an overall time of $4 \mathrm{~h}$ for the complete process used herein (under $1 \mathrm{~h}$ for MAF filtration and centrifugal ultrafiltration, followed by DNA extraction and qPCR quantification $3 \mathrm{~h}$ ), this method provides a rapid detection of $P$. aeruginosa compared with culture methods which take at least $24 \mathrm{~h}$. Other cultureindependent detection methods such as flow cytometry [33], immunoassays [34], Raman spectroscopy [35], and Fourier transform infrared spectroscopy [36] could be used as well. Further optimization of filtration parameters will be done to allow for future use of culture as an additional confirmatory quantification method. As shown in this work, MAF filtration is a very versatile tool that can be optimized in many ways to suit one's specific needs. It allows for the rapid enrichment of bacteria from different environmental sample types such as tap water but also process waters and other samples with challenging matrices and can be combined with various detection methods. The results presented herein are very promising for future routine application of MAF filtration in screening applications for $P$. aeruginosa in households and the environment as well as in the assessment of efficiency of disinfection measures in technical facilities and water systems.

Acknowledgments The authors want to thank Julia Neumair, Elisabeth von der Esch, and Katharina Sollweck for extensive discussions. Christine Benning kindly performed the FESEM measurements.

Author contributions L. Göpfert and J. Klüpfel conceived the experiments. J. Klüpfel and C. Heinritz conducted the experiments. L.Göpfert und J. Klüpfel analyzed the results. L. Göpfert wrote the manuscript with input from all co-authors. M. Elsner and M. Seidel supervised the project and were responsible for funding acquisition and resources.

Funding Open Access funding enabled and organized by Projekt DEAL. This project was funded by the Institute of Hydrochemistry at the Technical University of Munich.

\section{Compliance with ethical standards}

Conflict of interest The authors declare that they have no conflict of interest.

Open Access This article is licensed under a Creative Commons Attribution 4.0 International License, which permits use, sharing, adaptation, distribution and reproduction in any medium or format, as long as you give appropriate credit to the original author(s) and the source, provide a link to the Creative Commons licence, and indicate if changes were made. The images or other third party material in this article are included in the article's Creative Commons licence, unless indicated otherwise in a credit line to the material. If material is not included in the article's Creative Commons licence and your intended use is not permitted by statutory regulation or exceeds the permitted use, you will need to obtain permission directly from the copyright holder. To view a copy of this licence, visit http://creativecommons.org/licenses/by/4.0/.

\section{References}

1. Sproß J, Sinz A. Monolithic media for applications in affinity chromatography. J Sep Sci. 2011;34:1958-73. https://doi.org/10.1002/ jssc. 201100400 .

2. Walsh Z, Paull B, Macka M. Inorganic monoliths in separation science: a review. Anal Chim Acta. 2012;750:28-47. https://doi. org/10.1016/j.aca.2012.04.029.

3. Acquah C, Moy CKS, Danquah MK, Ongkudon CM. Development and characteristics of polymer monoliths for advanced LC bioscreening applications: a review. J Chromatogr B Anal Technol Biomed Life Sci. 2016;1015-1016:121-34. https:// doi.org/10.1016/j.jchromb.2016.02.016.

4. Bracken CL, Hendricks CW, Harding AK. Apparent bias in river water inoculum following centrifugation. J Microbiol Methods. 2006;67:304-9. https://doi.org/10.1016/j.mimet.2006.04.003.

5. Abdel-Hamid I, Ivnitski D, Atanasov P, Wilkins E. Flow-through immunofiltration assay system for rapid detection of $E$. coli O157: H7. Biosens Bioelectron. 1999;14:309-16. https://doi.org/10.1016/ S0956-5663(99)00004-4.

6. Sung YJ, Suk HJ, Sung HY, Li T, Poo H, Kim MG. Novel antibody/gold nanoparticle/magnetic nanoparticle nanocomposites for immunomagnetic separation and rapid colorimetric detection of 
Staphylococcus aureus in milk. Biosens Bioelectron. 2013;43:4329. https://doi.org/10.1016/j.bios.2012.12.052.

7. Zhang Y, Riley LK, Lin M, Hu Z. Determination of low-density Escherichia coli and Helicobacter pylori suspensions in water. Water Res. 2012;46:2140-8. https://doi.org/10.1016/j.watres. 2012.01.030.

8. Kunze A, Pei L, Elsässer D, Niessner R, Seidel M. High performance concentration method for viruses in drinking water. J Virol Methods. 2015;222:132-7. https://doi.org/10.1016/j.jviromet. 2015.06.007.

9. Wunderlich A, Torggler C, Elsässer D, Lück C, Niessner R, Seidel M. Rapid quantification method for Legionella pneumophila in surface water. Anal Bioanal Chem. 2016;408:2203-13. https:// doi.org/10.1007/s00216-016-9362-x.

10. Peskoller C, Niessner R, Seidel M. Development of an epoxy-based monolith used for the affinity capturing of Escherichia coli bacteria. J Chromatogr A. 2009;1216:3794-801. https://doi.org/10.1016/j. chroma.2009.02.041.

11. Elsäßer D, Ho J, Niessner R, Tiehm A, Seidel M. Heterogeneous asymmetric recombinase polymerase amplification (haRPA) for rapid hygiene control of large-volume water samples. Anal Biochem. 2018;546:58-64. https://doi.org/10.1016/j.ab.2018.01. 032.

12. Hall AN, Hogg SD, Phillips GO. Gradient elution of Salmonella typhimurium and Escherichia coli strains from a DEAE-cellulose column. J Appl Bacteriol. 1976;41:189-92. https://doi.org/10. 1111/j.1365-2672.1976.tb00618.x.

13. Pei L, Rieger M, Lengger S, Ott S, Zawadsky C, Hartmann NM, et al. Combination of crossflow ultrafiltration, monolithic affinity filtration, and quantitative reverse transcriptase PCR for rapid concentration and quantification of model viruses in water. Environ Sci Technol. 2012;46:10073-80. https://doi.org/10.1021/es302304t.

14. Ott S, Niessner R, Seidel M. Preparation of epoxy-based macroporous monolithic columns for the fast and efficient immunofiltration of Staphylococcus aureus. J Sep Sci. 2011;34: 2181-92. https://doi.org/10.1002/jssc.201100208.

15. Breidenstein EBM, de la Fuente-Núñez C, Hancock REW. Pseudomonas aeruginosa: all roads lead to resistance. Trends Microbiol. 2011;19:419-26. https://doi.org/10.1016/j.tim.2011. 04.005 .

16. Streeter K, Katouli M. Pseudomonas aeruginosa: a review of their pathogenesis and prevalence in clinical settings and the environment. Infect Epidemiol Med. 2016;2:25-32. https://doi.org/10. 18869/modares.iem.2.1.25.

17. De Beer D, Srinivasan R, Stewart PS. Direct measurement of chlorine penetration into biofilms during disinfection. Appl Environ Microbiol. 1994;60:4339-44. https://doi.org/10.1128/aem.60.12. 4339-4344.1994.

18. Cochran WL, McFeters GA, Stewart PS. Reduced susceptibility of thin Pseudomonas aeruginosa biofilms to hydrogen peroxide and monochloramine. J Appl Microbiol. 2000;88:22-30. https://oi. org/10.1046/j.1365-2672.2000.00825.x.

19. Wang H, Masters S, Hong Y, Stallings J, Falkinham JO, Edwards MA, Pruden A. Effect of disinfectant, water age, and pipe material on occurrence and persistence of legionella, mycobacteria, pseudomonas aeruginosa, and two amoebas. Environ Sci Technol. 2012;46:11566-74. https://doi.org/10.1021/es303212a.

20. Falkinham JO, Pruden A, Edwards M. Opportunistic premise plumbing pathogens: increasingly important pathogens in drinking water. Pathogens. 2015;4:373-86. https://doi.org/10.3390/ pathogens 4020373.

21. Kruse K. Wasserzähler in Hamburg mit Krankenhauskeimen verseucht. In: Hamburg. Abendblatt. 2014. https://www.
abendblatt.de/hamburg/article131969509/Wasserzaehler-inHamburg-mit-Krankheitskeimen-verseucht.html

22. Aumeran C, Paillard C, Robin F, Kanold J, Baud O, Bonnet R, Souweine B, Traore O. Pseudomonas aeruginosa and Pseudomonas putida outbreak associated with contaminated water outlets in an oncohaematology paediatric unit. J Hosp Infect. 2007:65:47-53. https://doi.org/10.1016/j.jhin.2006.08.009.

23. Costa D, Bousseau A, Thevenot S, Dufour X, Laland C, Burucoa C, Castel O. Nosocomial outbreak of Pseudomonas aeruginosa associated with a drinking water fountain. J Hosp Infect. 2015;91:2714. https://doi.org/10.1016/j.jhin.2015.07.010.

24. The Regulation and Quality Improvement Authority independent review of incidents of Pseudomonas aeruginosa infection in neonatal units in Northern Ireland Final Report 2012.

25. Kinsey CB, Koirala S, Solomon B, Rosenberg J, Robinson BF, Neri A, Laufer Halpin A, Arduino MJ, Moulton-Meissner H, Noble-Wang J, Chea N, Gould CV. Pseudomonas aeruginosa outbreak in a neonatal intensive care unit attributed to hospital tap water. Infect Control Hosp Epidemiol. 2017;38:801-8. https://doi. org/10.1017/ice.2017.87.

26. Pereira RPA, Peplies J, Mushi D, Brettar I, Höfle MG. Pseudomonas-specific NGS assay provides insight into abundance and dynamics of Pseudomonas species including P. aeruginosa in a cooling tower. Front Microbiol. 2018;9:1-15. https://doi.org/10. 3389/fmicb.2018.01958.

27. Grobe S, Wingender J, Trüper HG. Characterization of mucoid Pseudomonas aeruginosa strains isolated from technical water systems. J Appl Bacteriol. 1995;79:94-102. https://doi.org/10.1111/j. 1365-2672.1995.tb03129.x.

28. Zhang S, Ye C, Lin H, Lv L, Yu X. UV disinfection induces a Vbnc state in Escherichia coli and Pseudomonas aeruginosa. Environ Sci Technol. 2015;49:1721-8. https://doi.org/10.1021/es505211e.

29. Bédard E, Charron D, Lalancette C, Déziel E, Prévost M. Recovery of Pseudomonas aeruginosa culturability following copper- and chlorine-induced stress. FEMS Microbiol Lett. 2014;356:226-34. https://doi.org/10.1111/1574-6968.12494.

30. Pier GB. Pseudomonas aeruginosa lipopolysaccharide: a major virulence factor, initiator of inflammation and target for effective immunity. Int J Med Microbiol. 2007;297:277-95. https://doi.org/10. 1016/j.ijmm.2007.03.012.

31. Tanner RS, James SA. Rapid bactericidal effect of low $\mathrm{pH}$ against Pseudomonas aeruginosa. J Ind Microbiol. 1992;10:229-32. https://doi.org/10.1007/BF01569771.

32. Salehi B, Mehrabian S, Sepahi AA. The efficacy of cadmium oxide nanoparticles on Pseudomonas aeruginosa bacteria. Adv Stud Biol. 2013;5:473-88. https://doi.org/10.12988/asb.2013.31043.

33. Kennedy D, Wilkinson MG. Application of flow cytometry to the detection of pathogenic bacteria. Curr Issues Mol Biol. 2017;23: 21-38. https://doi.org/10.21775/cimb.023.021.

34. Seidel M, Niessner R. Chemiluminescence microarrays in analytical chemistry: a critical review. Anal Bioanal Chem. 2014;406: 5589-612. https://doi.org/10.1007/s00216-014-7968-4.

35. Pahlow S, Meisel S, Cialla-May D, Weber K, Rösch P, Popp J. Isolation and identification of bacteria by means of Raman spectroscopy. Adv Drug Deliv Rev. 2015;89:105-20. https://doi.org/10. 1016/j.addr.2015.04.006.

36. Novais Â, Freitas AR, Rodrigues C, Peixe L. Fourier transform infrared spectroscopy: unlocking fundamentals and prospects for bacterial strain typing. Eur J Clin Microbiol Infect Dis. 2019;38: 427-48. https://doi.org/10.1007/s10096-018-3431-3.

Publisher's note Springer Nature remains neutral with regard to jurisdictional claims in published maps and institutional affiliations. 